\title{
To copy or not to copy: the influence of instructions in design fixation experiments
}

\author{
Luis Vasconcelos, Chih-Chun Chen, Eloise Taysom and Nathan Crilly \\ University of Cambridge, UK
}

Design fixation experiments often require participants to solve a design problem whilst being exposed to an example solution and instructions for how to treat that example. However, little is known about the influence of such instructions, leading to difficulties in interpreting results and understanding how the introduction of examples affects idea generation. In our experiment, participants were all provided with the same design problem and example solution, but were presented with different instructions, ranging from strongly encouraging copying the example to strongly discouraging copying. Analyses of participants' work indicated that only the instructions encouraging copying had an effect. When encouraged to copy, participants tended to only copy the structural features of the example rather than the underlying concept. By contrast, the number of features copied was not reduced when participants were discouraged from copying. These findings suggest that there are subtle interactions between instructions and stimuli that influence design fixation.

\section{Introduction}

Inspiration is vital to creative design. This has driven design researchers to conduct many studies into inspiration, for instance to find out what materials inspire designers [1], how designers achieve inspiration [2], and how inspiration can improve designers' performance [3]. Many of these studies have observed the use of external stimuli during idea generation, and have reported that whilst external stimuli can assist idea generation, they can also hinder it. This detrimental effect of inspiration is described in the design literature as 'design fixation' [4]. Design fixation was originally studied in 
situations where the stimuli represented possible design solutions to the problem that was being addressed. It is often measured in the solutions that the designers propose according to the repetition of features from the stimuli that the designers see [4-10]. Although reproducing the features of good designs might be beneficial or efficient, the researchers have found that repetition is still present when the stimuli contain flawed inspiration sources, which they had thought designers would identify and avoid [4, 7, $10]$.

In general, fixation research suggests that blindly copying features from stimuli is harmful to idea generation, and therefore to the design process itself. As such, some studies have incorporated constraining textual instructions into the stimuli given to participants, to prevent them from copying features. However, the efficacy of the instructions seemed to vary across different accounts: they were effective in some cases [11,12] and ineffective in others $[4,13]$. Thus, it is still uncertain how textual instructions can influence the copying behaviour, and this uncertainty might be attributed to different factors. For instance, people may tend to overlook instructions presented along with example material [14], they can interpret the instructions in different ways if instructions are not strict, or wonder why they are being exposed to the stimuli and change their idea generation process accordingly. Whatever the reason might be, it is important to understand the relevance of the instructions provided to designers as part of the inspiration material. Methodologically, this would help in determining how fixation studies should be conducted and the results interpreted. More practically, it would also help to better understand how stimuli should be presented in software tools that aim to help idea generation by providing external stimuli to designers, and in other contexts in which designers are stimulated with examples (for such tools, see [15-17]).

In order to better understand the influence of instructions on idea generation, we conducted an experiment in which participants in different treatment conditions were provided with the same design problem and the same stimuli, but the instructions they were given with respect to that solution differed between the groups. In reporting on that experiment we offer insights that are useful for interpreting the existing inspiration and fixation studies, and for designing new ones. These insights are also relevant for considering how inspirational material might best be presented to designers outside of experimental contexts, for example where computer tools are used to index and retrieve inspirational material. 


\section{Inspiration, fixation and the introduction of inspiration sources}

Design researchers have been studying many different aspects of the inspiration process, including properties of the inspiration sources (e.g. quantity of sources) and aspects of the design process (e.g. total time available) [18]. One of the stimuli characteristics that has been studied is whether good and bad examples would be copied indiscriminately. Researchers wanted to know whether designers would fixate on the examples they see and would copy them to some extent, irrespective of their quality. Indeed, a series of studies has found that participants still replicated features from previous examples even though they were flawed $[4,7,10,11,19,20]$. To counteract this indiscriminate replication, some studies have tried warning participants about the flaws in the examples $[4,11,20]$, while others have tried instructing participants not to copy the examples [13, 21, 22]. Considering these two approaches, Chrysikou \& Weisberg [11] found that warning participants of flaws in the examples was not enough; they had to be told to avoid repeating those flaws. Yilmaz et al. [22] also reported telling participants not to reproduce the examples and found that feature repetition was reduced. Conversely, Jansson \& Smith [4] and Perttula \& Sipilä [13] found fixation effects even when participants were instructed to avoid using features from the examples provided. As such, surveying the published literature reveals conflicting results relating to the use of instructions when providing stimuli to designers.

Whilst many variables have been manipulated in fixation experiments, and some studies have already tested the effectiveness of using textual instructions to some extent, the way the stimuli are introduced in such experiments has not yet been studied systematically. Such stimuli introductions can typically be divided into two components: a descriptive statement on what the stimulus is (e.g. "here is an example solution") and a prescriptive instruction for how the stimulus should be used (e.g. "don't copy its features"). Currently, the stimuli introductions (i.e. descriptions and instructions) given to participants vary from study to study. For instance, participants have been told that the example should be considered a solution for the given problem [7], that it was provided to help them get started [6], that it was there to raise thoughts [23], and that it should be used to awaken thoughts but should not be reproduced [13] (also, sometimes the studies do not report how the stimuli were introduced). Such variation in the way the stimuli are provided can be attributed to a lack of agreement across studies about which 'real world' situation is being simulated (e.g. contexts in which examples are accidentally seen, intentionally searched for, or already known). Regardless of the reason, the variation in the way copying 
is encouraged or discouraged makes it difficult to know to what extent the design work is being influenced by such instructions. It could even be possible that designers will incorporate features from the examples provided irrespective of how constraining the instructions provided to them are.

To investigate the influence of stimuli instructions on idea generation, Smith et al. [21] did an experiment in which participants were asked to either conform to or diverge from the example solutions provided in a creative task. Some participants (group 1) were told that the examples were great ideas previously created for that task, and that participants should create ideas like those whilst not copying them exactly. Other participants (group 2) were told that the examples restricted people's creativity, and that participants should create ideas that were different to the examples. Finally, other participants (control group) were given the same examples but without any instructions. It was found that when compared to the ideas generated by participants in the control group, those in group 1 and in group 2 generated more ideas containing features from the examples and that groups 1 and 2 were not different in this respect. Based on these results, the researchers proposed that the participants did not conform to examples because they had assumed that they should; they conformed because they could not forget the examples that they had seen. However, the instructions used in the experiment were not strict (i.e. they suggested how ideas should be created, but did not forbid or require the use of features from the examples, allowing participants to interpret the information in different ways) and both the description of the stimuli and the instruction for their use varied between groups, making it difficult to infer the influence of each piece of information in isolation. We believe that a different experimental setup could provide research with more data, complementing the results previously found and helping the field to clarify the influence of the textual instructions used in experimental research and professional design practice. To investigate this, we designed and conducted an experiment to find out the effects of instructions in design inspiration and fixation, be the instructions neutral or either - slightly or very - encouraging or discouraging

\section{Methodology}

\section{Objective and hypothesis}

This experiment investigates how textual instructions accompanying external inspiration sources can shape the design work of the participants. In 
particular, we hypothesise that instructions provided along with external sources will not influence the ideas that participants generate.

\section{Experimental method}

Participants were randomly allocated to different experimental conditions. They were verbally asked to be creative and to design, individually, as many ideas as possible to a given problem. They were also asked to sketch and describe in writing their ideas on sheets of paper. Except for a control group that designed without any stimuli, all other experimental groups received a sketch of one example solution and a description of what the sketch represented. These stimulated groups received instructions for the use of features from the example, and these instructions varied with respect to how constraining or encouraging they were (see the materials section for the complete instructions). Finally, the authors assessed the participants' ideas to evaluate the influence of the instructions on the level of fixation demonstrated.

\section{Participants}

One hundred and sixty-eight first-year students in Engineering from the University of Cambridge, UK, were assigned to six experimental groups $(n=28)$. Participation in the experiment was part of the students' education, and was aimed at collecting data that could later be used to introduce them to the concept of design fixation. No demographic data was collected from the participants, but as first year undergraduate students they were broadly similar in age and design experience, drawn from a cohort with a malefemale ratio of $3: 1$.

\section{Task and problem}

The participants were told to solve the following problem. "Bicycles are a popular mode of transportation and recreation for many people. While growing up, a person might go through a series of ever-larger bikes, sometimes having several models, one after the other. However, having several bikes can be a problem for many reasons. Your task is to generate as many ideas as possible to eliminate the need to have multiple bikes as people grow up."

This problem was selected because it was expected to satisfy the following three criteria. First, it was unlikely that the participants had designed solutions to it before, although they were likely to have experienced the situation described in the problem previously (i.e. while growing up, they probably had multiple bikes), therefore helping their understanding of it. 
Second, the problem could be solved in many different ways, with many different underlying principles being applied, thus leaving enough room for creativity. Finally, both the design brief and the potential ideas held a low level of complexity, thus being suitable for a quick experiment fitting with the constraints of the course.

\section{Procedure (overview)}

The experiment took place in a large lecture theatre with all the participants present. During the first five minutes, the participants listened to an oral explanation about the activities to follow and received all the material they needed. Participants in the five stimulated groups (SGs) received the design brief, the inspiration source, and blank sheets of paper, whilst participants in the control group (CG) received the brief without any inspiration source. Then, the participants were asked to think of ideas for three minutes without actually committing any designs to paper (because different participants had different materials and content, this ensured they all had enough time to read all the materials and start developing some ideas). Finally, for the remaining ten minutes, all participants individually generated as many ideas as possible in silence, ideally including both a sketch and a written description for each idea.

\section{Materials}

All participants received the same design problem written on an A4 sheet, as well as blank A4 sheets to sketch and annotate their own ideas. Except for the participants in the control group, all participants received one additional sheet with an example solution, i.e. an annotated sketch of a bike (Figure 1). 


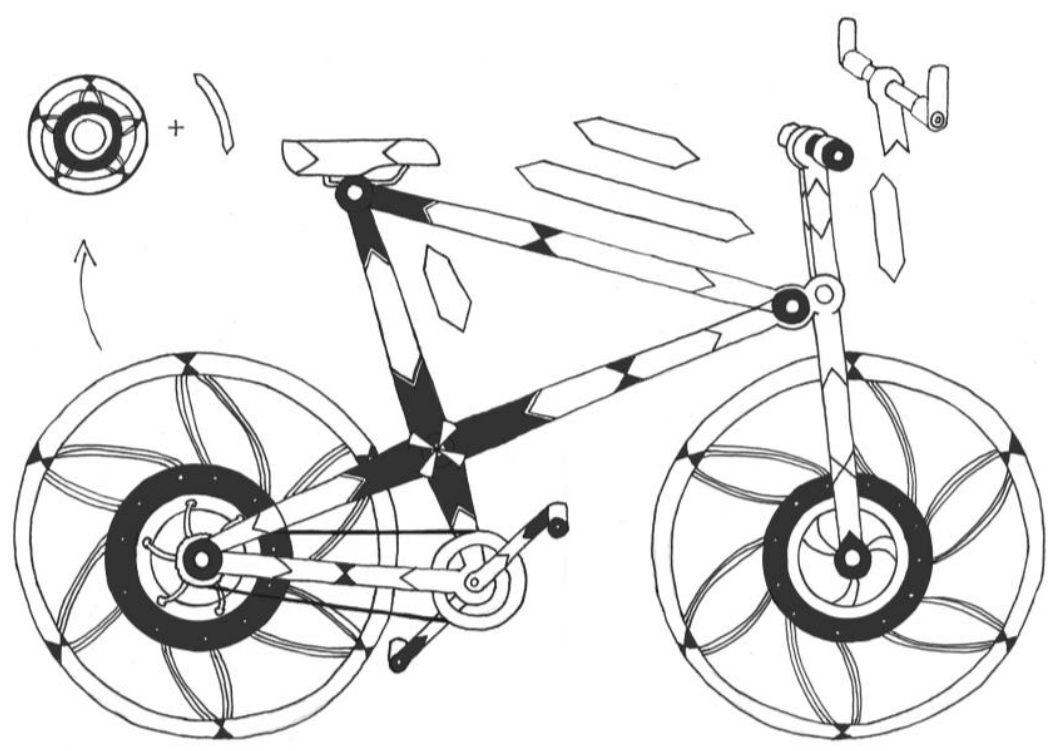

Fig1. Example solution provided to participants along with the following description. "A modular bike with parts of various sizes that can be connected and swapped to fit people with very different heights. Apart from the socketing parts and expansible/contractible wheels, the angles between tubes can also be modified in specific joints". The sketch used is a modification of the ECO 07 Compactable Urban Bicycle [24].

The example solution was preceded with the description: "Below is an example of how you should present your ideas (i.e. annotated sketches)". This description was either immediately followed by an instruction regarding the use of features from the examples (constraining or encouraging) or by no instruction whatsoever. The instructions for the different experimental groups are listed below against a code for each experimental group. - SG2-2 (strictly forbidding): "make sure you do not use features from this example in your own work".

- SG-1 (constraining): "avoid using features from this example in your own work".

- SG0 (neutral): no instruction was given.

- $\mathrm{SG}+1$ (encouraging): "consider using features from this example in your own work".

- $\mathrm{SG}+2$ (strictly requiring): "make sure you use features from this example in your own work". 


\section{Analysis}

The assessment of the participant's ideas was conducted by the first three authors of this study, with backgrounds in design, computer science, and mechanical engineering respectively. Initially, the three evaluators agreed on the metrics to be included in the analysis. After that, the three evaluators analysed the design work of a random experimental group together in order to agree on the assessment method, ultimately reaching a consensus with respect to how to interpret and assess the ideas. Finally, each of the evaluators individually judged a subset of the remaining ideas. If any evaluator had trouble judging an idea, this idea was then discussed collectively. This interactive assessment method was intended to offer a reliable analysis of the ideas; but because there was no redundancy in the assessment, no inter-rater agreement could be calculated. We considered 'one idea' either to be a sketch or a written description (usually both) that presented an understandable way to solve the problem. Participants often generated more than one idea, but in some cases all ideas could be considered as one, particularly when the idea was a bike. For instance, if the ideas could all be incorporated onto the same bike without interference, then they were considered as a single idea. Conversely, if there were two or more ideas for the same bike component (e.g. frame, wheel, handle bar), then they were considered to be distinct ideas.

The metrics used in the assessment were 'idea fluency' and idea 'repetition'. Idea fluency is the total number of ideas generated, also called 'quantity' elsewhere [25]. Idea repetition might happen in different levels, for instance, the repetition of idea types, conceptual features, or structural features. With respect to the idea type, we divided the ideas into two broad categories: bike and non-bike ideas, thus by designing a bike the participant would be repeating the idea type. With respect to their conceptual features, we also divided the ideas into two categories: modular or nonmodular ideas, thus by designing a modular idea the participant would be repeating the conceptual feature. Finally, we examined the incorporation of structural features in the participants' ideas. These features were intentionally included into the example design in order to permit a measure of fixation. There were five structural features: swappable components to change bike size; frame joints (lugs) that act as sockets for the tubes; wheels with bendable spokes; an hourglass-shaped frame; and a saddle that cannot be adjusted in height directly.

Eight participants (4.8\%) either did not generate any idea or generated ideas that could not be interpreted by the authors; the results from such participants were not included in our analysis. The adjusted number of participants per experimental group is indicated in the following section. 


\section{Results and discussion}

\section{Idea fluency}

Instructions had no effect on the number of ideas generated. The data did not satisfy the assumptions for a standard ANOVA, therefore a nonparametic Kruskal-Wallis test equivalent to a one-way ANOVA was implemented instead. The results show that the number of ideas generated did not vary significantly across the five stimulated groups (SGs) $(H(4)=2.63$, $p=.62$ ). However, there is a significant difference in the idea fluency between participants in these groups and those in the control group (CG) $(H(5)=18.27, p<.01)$, with participants in the control group generating a greater number of ideas. Additionally, although the majority of participants in the stimulated groups had an idea fluency of 1, participants in the nonconstraining groups $(\mathrm{SG}, \mathrm{SG}+1$, and $\mathrm{SG}+2)$ had a higher frequency of fluencies greater than 1 (i.e. more participants in those groups generated more than one idea). However, this difference was not shown to be significant $\left(X^{2}(4)=19.85, p=.47\right)$. A significant difference in the frequency of idea fluencies was found between the stimulated groups and the control group $\left(X^{2}(5)=55.38, p<.001\right)$, with participants in the control group having a higher frequency of fluencies greater than 1 . Table 1 shows summary statistics for these results.

Table 1 Summary of ideas generated per participant and ideas frequencies across groups

\begin{tabular}{|l|c|c|c|c|c|c|}
\hline Generated ideas & SG-2 & SG-1 & SG0 & SG+1 & SG+2 & CG \\
\hline $\begin{array}{l}\text { Mean (and SD) for } \\
\text { the number of ideas } \\
\text { per participant }\end{array}$ & $\begin{array}{c}1.50 \\
(1.27)\end{array}$ & $\begin{array}{c}1.30 \\
(0.61)\end{array}$ & $\begin{array}{c}1.48 \\
(0.49)\end{array}$ & $\begin{array}{c}1.41 \\
(0.56)\end{array}$ & $\begin{array}{c}1.54 \\
(1.10)\end{array}$ & $\begin{array}{c}2.39 \\
(1.31)\end{array}$ \\
\hline $\begin{array}{l}\text { Range of ideas per } \\
\text { participant }\end{array}$ & $1-6$ & $1-3$ & $1-4$ & $1-4$ & $1-6$ & $1-5$ \\
\hline $\begin{array}{l}\text { Total number of } \\
\text { ideas }\end{array}$ & 39 & 35 & 40 & 38 & 43 & 67 \\
\hline $\begin{array}{l}\text { Participants with 1 } \\
\text { idea (and \%) }\end{array}$ & $\begin{array}{c}21 \\
(80.8 \%)\end{array}$ & $\begin{array}{c}21 \\
(77.8 \%)\end{array}$ & $\begin{array}{c}16 \\
(59.3 \%)\end{array}$ & $\begin{array}{c}19 \\
(70.4 \%)\end{array}$ & $\begin{array}{c}19 \\
(67.9 \%)\end{array}$ & $\begin{array}{c}11 \\
(39.3 \%)\end{array}$ \\
\hline $\begin{array}{l}\text { Participants with 2 } \\
\text { ideas (and \%) }\end{array}$ & $\begin{array}{c}2 \\
(7.7 \%)\end{array}$ & $\begin{array}{c}4 \\
(14.8 \%)\end{array}$ & $\begin{array}{c}10 \\
(37 \%)\end{array}$ & $\begin{array}{c}6 \\
(22.2 \%)\end{array}$ & $\begin{array}{c}7 \\
(25 \%)\end{array}$ & $\begin{array}{c}3 \\
(10.7 \%)\end{array}$ \\
\hline $\begin{array}{l}\text { Participants with 3 } \\
\text { ideas (and \%) }\end{array}$ & $\begin{array}{c}1 \\
(3.9 \%)\end{array}$ & $\begin{array}{c}2 \\
(7.4 \%)\end{array}$ & $\begin{array}{c}0 \\
(0.0 \%)\end{array}$ & $\begin{array}{c}1 \\
(3.7 \%)\end{array}$ & $\begin{array}{c}0 \\
(0.0 \%)\end{array}$ & $\begin{array}{c}7 \\
(25 \%)\end{array}$ \\
\hline $\begin{array}{l}\text { Participants with 4 } \\
\text { ideas (and \%) }\end{array}$ & $\begin{array}{c}0 \\
(0.0 \%)\end{array}$ & $\begin{array}{c}0 \\
(0.0 \%)\end{array}$ & $\begin{array}{c}1 \\
(3.7 \%)\end{array}$ & $\begin{array}{c}1 \\
(3.7 \%)\end{array}$ & $\begin{array}{c}1 \\
(3.6 \%)\end{array}$ & $\begin{array}{c}6 \\
(21.4 \%)\end{array}$ \\
\hline
\end{tabular}




\begin{tabular}{|l|c|c|c|c|c|c|}
\hline $\begin{array}{l}\text { Participants with 5 } \\
\text { ideas (and \%) }\end{array}$ & $\begin{array}{c}1 \\
(3.9 \%)\end{array}$ & $\begin{array}{c}0 \\
(0.0 \%)\end{array}$ & $\begin{array}{c}0 \\
(0.0 \%)\end{array}$ & $\begin{array}{c}0 \\
(0.0 \%)\end{array}$ & $\begin{array}{c}0 \\
(0.0 \%)\end{array}$ & $\begin{array}{c}1 \\
(3.6 \%)\end{array}$ \\
\hline $\begin{array}{l}\text { Participants with 6 } \\
\text { ideas (and \%) }\end{array}$ & $\begin{array}{c}1 \\
(3.9 \%)\end{array}$ & $\begin{array}{c}0 \\
(0.0 \%)\end{array}$ & $\begin{array}{c}0 \\
(0.0 \%)\end{array}$ & $\begin{array}{c}0 \\
(0.0 \%)\end{array}$ & $\begin{array}{c}1 \\
(3.6 \%)\end{array}$ & $\begin{array}{c}0 \\
(0.0 \%)\end{array}$ \\
\hline $\begin{array}{l}\text { Total number of } \\
\text { participants }\end{array}$ & 26 & 27 & 27 & 28 & 28 & 28 \\
\hline
\end{tabular}

These results reveal that the idea generation rate was not influenced by how encouraging or constraining the instructions were. However, the presence of an example design affected idea generation: designing without exposure to stimuli resulted in more ideas being generated, which we interpret as a benefit of isolation from examples. This effect is consistent with other studies in which seeing an example caused reduction in the idea fluency [7], although studies have also reported an increase in the idea fluency as a result from external stimulation [26] or even no effect at all [4]. Finally, we should mention that although all groups were asked to present their ideas with both sketches and textual descriptions, the control group produced many ideas that were presented only in text. Thus, it is possible that the control group created more ideas because they did not spend their time sketching every idea.

\section{Repetition of the idea type}

Instructions had no effect on the number of bike ideas. The data did not satisfy the assumptions for a standard ANOVA, therefore a KruskalWallis test was is implemented instead. The results show that the number of bike ideas generated did not vary significantly across the five stimulated groups (SGs) $(H(4)=2.98, p=.56)$, nor between these groups and the control group (CG) $(H(5)=3.55, p=.62)$. Consistent with these results, there is also no significant difference in the proportion of bike ideas generated (compared to non-bike ideas) across the five stimulated groups $\left(X^{2}(4)=2.53, p=.64\right)$. However, there is a significant difference in the proportions between these groups and the control group $\left(X^{2}(5)=32.73\right.$, $p=.001$ ), with participants in the control group having a greater proportion of non-bike ideas, such as other transportation means or policies to discourage the use and acquisition of bikes. Table 2 shows summary statistics for these results.

Table 2 Summary of bike and non-bike ideas generated across groups

\begin{tabular}{|l|c|c|c|c|c|c|}
\hline Bike Ideas & SG-2 & SG-1 & SG0 & SG+1 & SG+2 & CG \\
\hline Mean (and SD) for the & 1.27 & 1.15 & 1.33 & 1.33 & 1.29 & 1.43 \\
number of bike ideas per & $(0.92)$ & $(0.36)$ & $(0.83)$ & $(0.55)$ & $(0.53)$ & $(0.84)$ \\
\hline
\end{tabular}




\begin{tabular}{|l|c|c|c|c|c|c|}
\hline participant & & & & & & \\
\hline $\begin{array}{l}\text { Range of bike ideas per } \\
\text { participant }\end{array}$ & $0-5$ & $1-2$ & $0-4$ & $1-3$ & $0-2$ & $0-3$ \\
\hline $\begin{array}{l}\text { Number of bike ideas } \\
\text { (and \%) }\end{array}$ & $\begin{array}{c}33 \\
(85 \%)\end{array}$ & $\begin{array}{c}31 \\
(89 \%)\end{array}$ & $\begin{array}{c}36 \\
(90 \%)\end{array}$ & $\begin{array}{c}36 \\
(95 \%)\end{array}$ & $\begin{array}{c}36 \\
(84 \%)\end{array}$ & $\begin{array}{c}40 \\
(60 \%)\end{array}$ \\
\hline $\begin{array}{l}\text { Number of non-bike ide- } \\
\text { as (and \%) }\end{array}$ & $\begin{array}{c}6 \\
(15 \%)\end{array}$ & $\begin{array}{c}4 \\
(11 \%)\end{array}$ & $\begin{array}{c}4 \\
(10 \%)\end{array}$ & $\begin{array}{c}2 \\
(5 \%)\end{array}$ & $\begin{array}{c}7 \\
(16 \%)\end{array}$ & $\begin{array}{c}27 \\
(40 \%)\end{array}$ \\
\hline
\end{tabular}

If we adopt a bike and non-bike categorisation for the ideas generated, these results reveal that the type of idea generated was not influenced by the instructions. Additionally, the presence of the bike example did not increase the number of bike ideas either. However, whilst the number of bike ideas was roughly the same for all groups, there was a large difference in the proportion of bike ideas between the control and stimulated groups. Only $60 \%$ of all ideas generated by the control group were bikes, whereas the stimulated groups had a much greater proportion of bike ideas $(89 \%$ on average). The results indicate that bike ideas were equally likely to be generated irrespective of the experimental condition, but not seeing the example allowed participants from the control group to explore different areas of the solution space, again confirming the beneficial isolation effect. This effect is broadly consistent with other studies in which seeing an example caused participants to conform to certain types of solutions, thus reducing the diversity of ideas $[4,5,7]$.

\section{Repetition of the conceptual feature}

Instructions had no effect on the number of modular ideas. The data did not satisfy the assumptions for a standard ANOVA, therefore a KruskalWallis test was is implemented instead. The results show that the number of modular ideas generated did not vary significantly across the five stimulated groups (SGs) $(H(4)=4.21, p=.38)$. However, there appears to be a significant difference in the repetition of modularity between the stimulated groups and the control group (CG) $(H(5)=11.40, p<.05)$, with participants in the control group creating a greater number of modular ideas. When looking at the frequencies, there is no significant difference in the proportion of modular ideas generated (compared to non-modular ideas) across the five stimulated groups $\left(X^{2}(4)=5.12, p=.27\right)$, nor even when the control group is included in the comparison $\left(X^{2}(5)=5.68, p=.34\right)$. Table 3 shows summary statistics for these results.

Table 3 Summary of modular and non-modular ideas generated across groups

\begin{tabular}{|l|l|l|l|l|l|l|}
\hline Modular ideas & SG-2 & SG-1 & SG0 & SG+1 & SG+2 & CG \\
\hline
\end{tabular}




\begin{tabular}{|l|c|c|c|c|c|c|}
\hline $\begin{array}{l}\text { Mean (and SD) for the number } \\
\text { of modular ideas per participant }\end{array}$ & $\begin{array}{c}0.08 \\
(0.27)\end{array}$ & $\begin{array}{c}0.3 \\
(0.47)\end{array}$ & $\begin{array}{c}0.19 \\
(0.40)\end{array}$ & $\begin{array}{c}0.19 \\
(0.40)\end{array}$ & $\begin{array}{c}0.18 \\
(0.39)\end{array}$ & $\begin{array}{c}0.43 \\
(0.50)\end{array}$ \\
\hline $\begin{array}{l}\text { Range of modular ideas per } \\
\text { participant }\end{array}$ & $0-1$ & $0-1$ & $0-1$ & $0-1$ & $0-1$ & $0-1$ \\
\hline $\begin{array}{l}\text { Number of modular ideas (and } \\
\%)\end{array}$ & $\begin{array}{c}2 \\
(5 \%)\end{array}$ & $\begin{array}{c}8 \\
(23 \%)\end{array}$ & $\begin{array}{c}5 \\
(13 \%)\end{array}$ & $\begin{array}{c}5 \\
(13 \%)\end{array}$ & $\begin{array}{c}5 \\
(12 \%)\end{array}$ & $\begin{array}{c}12 \\
(18 \%)\end{array}$ \\
\hline $\begin{array}{l}\text { Number of non-modular ideas } \\
\text { (and \%) }\end{array}$ & $\begin{array}{c}37 \\
(95 \%)\end{array}$ & $\begin{array}{c}27 \\
(77 \%)\end{array}$ & $\begin{array}{c}35 \\
(87 \%)\end{array}$ & $\begin{array}{c}33 \\
(87 \%)\end{array}$ & $\begin{array}{c}38 \\
(88 \%)\end{array}$ & $\begin{array}{c}55 \\
(82 \%)\end{array}$ \\
\hline
\end{tabular}

If we adopt a modular and non-modular categorisation for the ideas generated, these results reveal that the type of idea generated was not influenced by the instructions. In fact, modular ideas were extremely rare across all groups. However, the results suggest that the presence of an example design affected idea generation and the control group created on average more modular ideas than the stimulated groups. This apparently surprising result can be attributed to a higher overall number of ideas generated by the control group, which is supported by there being no difference in the proportion of modular ideas generated among all groups. Still, the fixation literature would suggest that the stimulated groups would generate more modular ideas, an effect similar to the repetition of the idea type (i.e. bikes). In particular, participants in $\mathrm{SG}+1$ and $\mathrm{SG}+2$ were encouraged to use features from the example in their own work (and modularity was a visible feature on the example provided) but the results from those groups do not indicate that they acted accordingly. Similarly, participants in SG-2 and $\mathrm{SG}^{-1}$ were discouraged from using features from the example but generated as many modular ideas as the other groups. One possible explanation for this is that instructions have no influence on idea generation, as we had previously hypothesised. However, as there was no difference in the proportion of modular ideas between control and stimulated groups, we believe that the general principle of modularity (included in the example as a conceptual feature) was less obvious than the structural features and thus did not induce fixation effects.

\section{Repetition of structural features}

Instructions had a significant effect on the number of ideas that contained the structural features of the example provided. The data did not satisfy the assumptions for a standard ANOVA, therefore a Kruskal-Wallis test was implemented instead. The results show that the number of structural features incorporated into the participants' ideas varied significantly across the five stimulated groups (SG) $(\underline{H}(4)=41.62, p<.001)$ and between these 
groups and the control group $(\mathrm{CG})(H(5)=54.63 ; \mathrm{p}<.001)$, with participants in the encouraged groups ( $\mathrm{SG}+1$ and $\mathrm{SG}+2)$ incorporating a greater number of structural features. Consistent with these results, there is also a significant difference in the relative number of ideas with structural features across the stimulated groups $\left(X^{2}(4)=37.32, p<.001\right)$, with a higher number of features being associated with positive instructions to copy. There is also a significant difference between these groups and the control group $\left(X^{2}(5)=49.74, \mathrm{p}<.001\right)$, with the control group's repetition rate being close to the neutrally stimulated group (SG0). Table 4 shows summary statistics for these results.

Table 4 Summary of features incorporated into the participants' ideas and frequencies of ideas with features across groups

\begin{tabular}{|l|c|c|c|c|c|c|}
\hline \multicolumn{1}{|c|}{ Feature } & SG-2 & SG-1 & SG0 & SG+1 & SG+2 & CG \\
\hline $\begin{array}{l}\text { Mean (and SD) for the } \\
\text { number features in- } \\
\text { corporated per idea }\end{array}$ & $\begin{array}{c}0.08 \\
(0.27)\end{array}$ & $\begin{array}{c}0.17 \\
(0.38)\end{array}$ & $\begin{array}{c}0.10 \\
(0.30)\end{array}$ & $\begin{array}{c}0.71 \\
(0.98)\end{array}$ & $\begin{array}{c}0.93 \\
(0.99)\end{array}$ & $\begin{array}{c}0.13 \\
(0.42)\end{array}$ \\
\hline $\begin{array}{l}\text { Range of features in- } \\
\text { corporated }\end{array}$ & $0-1$ & $0-1$ & $0-1$ & $0-3$ & $0-3$ & $0-2$ \\
\hline $\begin{array}{l}\text { Ideas with 0 features } \\
\text { (and \%) }\end{array}$ & 36 & $\begin{array}{c}29 \\
(92 \%)\end{array}$ & $\begin{array}{c}36 \\
(93 \%)\end{array}$ & $\begin{array}{c}22 \\
(98 \%)\end{array}$ & $\begin{array}{c}19 \\
(44 \%)\end{array}$ & $\begin{array}{c}60 \\
(90 \%)\end{array}$ \\
\hline $\begin{array}{l}\text { Ideas with 1 features } \\
\text { (and \%) }\end{array}$ & $\begin{array}{c}3 \\
(8 \%)\end{array}$ & $\begin{array}{c}6 \\
(17 \%)\end{array}$ & $\begin{array}{c}4 \\
(10 \%)\end{array}$ & $\begin{array}{c}8 \\
(21 \%)\end{array}$ & $\begin{array}{c}11 \\
(26 \%)\end{array}$ & $\begin{array}{c}5 \\
(7 \%)\end{array}$ \\
\hline $\begin{array}{l}\text { Ideas with 2 features } \\
\text { (and \%) }\end{array}$ & $\begin{array}{c}0 \\
(0 \%)\end{array}$ & $\begin{array}{c}0 \\
(0 \%)\end{array}$ & $\begin{array}{c}0 \\
(0 \%)\end{array}$ & $\begin{array}{c}5 \\
(13 \%)\end{array}$ & $\begin{array}{c}10 \\
(23 \%)\end{array}$ & $\begin{array}{c}2 \\
(3 \%)\end{array}$ \\
\hline $\begin{array}{l}\text { Ideas with 3 features } \\
\text { (and \%) }\end{array}$ & $\begin{array}{c}0 \\
(0 \%)\end{array}$ & $\begin{array}{c}0 \\
(0 \%)\end{array}$ & $\begin{array}{c}0 \\
(0 \%)\end{array}$ & $\begin{array}{c}3 \\
(8 \%)\end{array}$ & $\begin{array}{c}3 \\
(7 \%)\end{array}$ & $\begin{array}{c}0 \\
(0 \%)\end{array}$ \\
\hline $\begin{array}{l}\text { Ideas with 4 features } \\
\text { (and \%) }\end{array}$ & $\begin{array}{c}0 \\
(0 \%)\end{array}$ & $\begin{array}{c}0 \\
(0 \%)\end{array}$ & $\begin{array}{c}0 \\
(0 \%)\end{array}$ & $\begin{array}{c}0 \\
(0 \%)\end{array}$ & $\begin{array}{c}0 \\
(0 \%)\end{array}$ & $\begin{array}{c}0 \\
(0 \%)\end{array}$ \\
\hline $\begin{array}{l}\text { Ideas with 5 features } \\
\text { (and \%) }\end{array}$ & $\begin{array}{c}0 \\
(0 \%)\end{array}$ & $\begin{array}{c}0 \\
(0 \%)\end{array}$ & $\begin{array}{c}0 \\
(0 \%)\end{array}$ & $\begin{array}{c}0 \\
(0 \%)\end{array}$ & $\begin{array}{c}0 \\
(0 \%)\end{array}$ & $\begin{array}{c}0 \\
(0 \%)\end{array}$ \\
\hline $\begin{array}{l}\text { Ideas with features in- } \\
\text { corporated (and \%) }\end{array}$ & $\begin{array}{c}3 \\
(8 \%)\end{array}$ & $\begin{array}{c}6 \\
(17 \%)\end{array}$ & $\begin{array}{c}4 \\
(10 \%)\end{array}$ & $\begin{array}{c}16 \\
(42 \%)\end{array}$ & $\begin{array}{c}23 \\
(56 \%)\end{array}$ & $\begin{array}{c}7 \\
(10 \%)\end{array}$ \\
\hline
\end{tabular}

These results reveal that encouraging instructions influenced the repetition or incorporation of conceptual features, an outcome that does not support our hypothesis. On average, participants in SG+1 and SG+2 incorporated more features per idea and generated more ideas that incorporated any feature. Additionally, participants in the strictly forbidden group, $\mathrm{SG}_{-}-2$, did not incorporate any structural feature from the example. However, participants in SG-1 did not follow this trend and produced results similar to the neutral and control groups. This result is partially consistent with research 
from Smith et al. [21] but inconsistent with Chrysikou \& Weisberg [11], as encouraging instructions increased fixation, whereas constraining instructions did not decrease it. However, contrary to the results from Smith et al. [21], our constrained groups did not replicate more features than a control group, contradicting the idea that participants could not forget the example they had seen. It seems that a few structural features were naturally likely to be incorporated into the ideas generated (supported by the similar results from SG-1, SG0 and CG), with SG+1 and SG+2 incorporating more features because instructed to do so. When comparing the results from the repetition of structural features to the repetition of the conceptual feature used in this study, we infer that concrete structural features can be more easily copied or can fixate more than abstract conceptual features from examples. This is similar to what has been suggested in previous studies [27, $28,29]$. Again, we should highlight that the control group produced proportionally less sketches than the other groups. This puts the other groups in an unfavourable position with respect to the count of structural features incorporated, since these groups had to represent a shape of the bike in which repetition could be more easily recognised - it is difficult to identify structural repetition when the idea is represented only by text - thus possibly biasing the results.

\section{Study limitations}

The main limitations of this study involve the duration of the generation session, the pool of participants chosen, the design problem used, and the assumptions for inter-rater agreement. These limitations are discussed next.

The idea generation session in this study was ten minutes long, which can be considered short when compared to other fixation studies in which generation sessions lasted for 30 or 60 minutes [30], and shorter still compared to professional practice [31]. Also, past research suggests [32], novel ideas tend to occur later in the idea generation session. As a result, the short session adopted for this study might have contributed to inflated fixation scores.

The participants in this study were undergraduate students and the generation session was part of an ongoing engineering course. This might have resulted in a more diligent participant behaviour when compared to other studies in which participants and experimenters did not have a student-lecturer relationship. As a result, the setup adopted for this study might have contributed to an increased participant adherence to the instructions. The design problem used in this study was chosen because it was unlikely that the participants had designed solutions to it before. As 
such, it is possible that using familiar problems will produce different results, although research has demonstrated that fixation effects can be observed with both familiar and unfamiliar problems [4].

Finally, in this study we did not measure the inter-rater agreement for the assessment, a test which is often performed for similar studies. Such measurement is important to demonstrate that the reliability of the evaluators' assessment when working individually. Whereas the assessment performed in this study involved many interactions between evaluators (thus we expected a high agreement between evaluators), we cannot quantify how good this agreement might have been, or even if there were varying levels of agreement for the different ideation metrics used in this study.

\section{Conclusion and future work}

In this study we have tested the influence of instructions on idea generation. In particular, we analysed how instructions may affect the number of ideas generated and the repetition or incorporation of the example or its parts into the participants' ideas. The instructions used were provided along with an external stimulus and its description. It is important to differentiate the descriptions from instructions because in this study we have controlled the former but manipulated the latter. We found that instructions had some influence on the idea generation of our participants. When asked to use features from the example, participants copied structural features but failed to copy a more abstract conceptual feature. When asked not to use features from the example, however, most participants did not reduce the number of features copied. This result allows us to infer that more concrete features are easier to recognise - and thus reproduce - than more abstract features, such as modularity. Also, it might indicate that positive instructions are more effective than negative ones, which can tell us how to frame future instructions, whether that is with respect to experimental stimuli in research or inspirational stimuli in design practice.

Irrespective of how constraining the instructions were, participants exhibited fixation effects due to their exposure to the example design (in comparison to the control group, all stimulated groups created more ideas of the same type as the example provided). This result is in line with many other design fixation experiments in which participants become stuck on a particular idea type. However, it is important to emphasise that the description of the stimulus itself could also be causing the fixation effect as the stimulus was presented to the participants as "an example of how they should present their ideas". Thus, perhaps there is an implicit suggestion 
for the participants to produce ideas similar to the example, i.e. a bike. Future studies could investigate such possibility and complement our understanding about stimuli introduction with the influence of the descriptions provided to designers.

In this study we observed that some results might have been influenced by participants communicating their ideas in different ways (some of them drawing, some writing, and some doing both), an issue that cannot be confirmed until the analysis of the results. In inspiration and fixation studies, participants are asked to provide their ideas according to a content template, but that is rarely compulsory. It is fundamental that all ideas contain the same elements (e.g. text and sketch) in order to be analysed and compared, so studies should make sure every idea has a similar content. Additionally, future studies could investigate the difference between providing written, pictorial or spoken instructions to designers, but also how they assimilate instructions. For instance, it is possible that people need instructions about the instructions (i.e. "read the instructions carefully"), as one way to make sure that they will read and fully understand what is required from them.

Finally, when considering design practice, the results reported here are relevant to how inspirational stimuli should be framed when presented to designers. This is particularly important for the development and implementation of computer-aided design tools that provide designers with external stimuli. Much has been researched on how such software tools might be structured and interacted with, and what form the inspirational stimuli should take $[33,34]$. However, it is also important to understand how those stimuli should be introduced, whether by description, instruction, or both. Should designers be steered towards or away from the repetition of structural features, directed to identify conceptual features, or simply left alone to interpret and respond as they see fit? By developing a better understanding of how stimuli instructions influence idea generation, we will move closer to answering such questions and thereby be more capable of supporting design activities.

\section{Acknowledgement}

The authors would like to thank Carlos Coimbra Cardoso for commenting on earlier drafts of this paper, to all the students for taking part in the experiment, and to the three DCC reviewers for improving this work with their feedback. This work was supported by the CAPES Foundation, Ministry of Education of Brazil, under grant/process: BEX 11468/13-0 and by the UK's Engineering and Physical Sciences Research Council 
(EP/K008196/1). Research data supporting this publication is available from the DSpace@Cambridge repository at the web address given below. It contains data from the participants and from our analysis. The data from the participants consists of all the annotated sketches that participants generated in the experiment. The data from the analysis consists of the evaluation for all ideas generated by the participants in the experiment.

https://www.repository.cam.ac.uk/handle/1810/254702

\section{References}

1. Gonçalves M, Cardoso C, Badke-Schaub P (2014) What inspires designers? Preferences on inspirational approaches during idea generation. Des Stud 35:29-53.

2. Zhao M (2013) Seek it or let it come: how designers achieve inspirations. In: CHI13 Ext. Abstr. Hum. Factors Comput. Syst. ACM, pp 2779-2784

3. Eckert CM (1997) Design inspiration and design performance. In: Proc. 78th World Conf. Text. Inst. Citeseer, pp 369-387

4. Jansson DG, Smith SM (1991) Design fixation. Des Stud 12:3-11.

5. Cardoso C, Badke-Schaub P (2011) The influence of different pictorial representations during idea generation. J Creat Behav 45:130-146.

6. Dahl DW, Moreau P (2002) The Influence and Value of Analogical Thinking during New Product Ideation. J Mark Res 39:47-60.

7. Linsey JS, Tseng I, Fu K, et al. (2010) A Study of Design Fixation, Its Mitigation and Perception in Engineering Design Faculty. J Mech Des 132:041003.

8. Purcell AT, Gero JS (1996) Design and other types of fixation. Des Stud 17:363-383.

9. Youmans RJ (2011) Design fixation in the wild: Design environments and their influence on fixation. J Creat Behav 45:101-107.

10. Youmans RJ (2011) The effects of physical prototyping and group work on the reduction of design fixation. Des Stud 32:115-138.

11. Chrysikou EG, Weisberg RW (2005) Following the Wrong Footsteps: Fixation Effects of Pictorial Examples in a Design Problem-Solving Task. J Exp Psychol Learn Mem Cogn 31:1134-1148.

12. Yilmaz S, Seifert CM, Gonzalez R (2010) Cognitive heuristics in design: Instructional strategies to increase creativity in idea generation. Artif Intell Eng Des Anal Manuf 24:335-355.

13. Perttula M, Sipilä $P$ (2007) The idea exposure paradigm in design idea generation. J Eng Des 18:93-102.

14. LeFevre J-A, Dixon P (1986) Do Written Instructions Need Examples? Cogn Instr 3:1-30.

15. Chakrabarti A, Sarkar P, Leelavathamma B, Nataraju BS (2005) A functional representation for aiding biomimetic and artificial inspiration of new ideas. Artif Intell Eng Des Anal Manuf 19:113-132. 
16. Linsey J, Wood K (2008) Wordtrees: A method for design-by-analogy. ASEE annual conference.

17. Vattam S, Wiltgen B, Helms M, et al. (2011) DANE: Fostering Creativity in and through Biologically Inspired Design. In: Taura T, Nagai Y (eds) Des. Creat. 2010. Springer London, pp 115-122

18. Sio UN, Kotovsky K, Cagan J (2015) Fixation or inspiration? A meta-analytic review of the role of examples on design processes. Des Stud 39:70-99.

19. Perttula MK, Liikkanen LA (2006) Exposure effects in design idea generation: unconscious conformity or a product of sampling probability. In: Proc. Nord. pp 42-55

20. Viswanathan V, Atilola O, Esposito N, Linsey J (2014) A study on the role of physical models in the mitigation of design fixation. J Eng Des 25:25-43.

21. Smith SM, Ward TB, Schumacher JS (1993) Constraining effects of examples in a creative generation task. Mem Cognit 21:837-845.

22. Yilmaz S, Seifert CM, Gonzalez R (2010) Cognitive heuristics in design: Instructional strategies to increase creativity in idea generation. Artif Intell Eng Des Anal Manuf 24:335-355.

23. Liikkanen LA, Perttula M (2010) Inspiring design idea generation: insights from a memory-search perspective. J Eng Des 21:545-560.

24. ECO 07 - Compactable Urban Bicycle. In: Behance. https://www.behance.net/gallery/293563/ECO-07-Compactable-UrbanBicycle. Accessed 10 Nov 2015

25. Shah JJ, Smith SM, Vargas-Hernandez N (2003) Metrics for measuring ideation effectiveness. Des Stud 24:111-134.

26. Purcell AT, Gero JS (1992) Artificial Intelligence in Design Conference 1991 Special Issue Effects of examples on the results of a design activity. Knowledge-Based Systems 5:82-91.

27. Zahner D, Nickerson JV, Tversky B, et al (2010) A fix for fixa-tion? Rerepresenting and abstracting as creative processes in the de-sign of information systems. Artificial Intelligence for Engineering Design, Analysis and Manufacturing 24:231-244.

28. Cheong H, Hallihan G, Shu LH (2014) Understanding Analogi-cal Reasoning in Biomimetic Design: An Inductive Approach. In: Gero JS (ed) Design Computing and Cognition '12. Springer Nether-lands, Dordrecht, pp 21-39.

29. Feng T, Cheong H, Shu LH (2014) Effects of Abstraction on Selecting Relevant Biological Phenomena for Biomimetic Design. Journal of Mechanical Design 136:111111.

30. Vasconcelos LA, Crilly N (2016) Inspiration and fixation: Questions, methods, findings, and challenges. Design Studies 42:1-32.

31. Crilly N (2015) Fixation and creativity in concept development: The attitudes and practices of expert designers. Design Studies 38:54-91.

32. Kudrowitz B, Dippo C (2013) Getting to the novel ideas: exploring the alternative uses test of divergent thinking. In: ASME 2013 International Design Engineering Technical Conferences and Computers and Information in Engineering Conference. American Society of Mechanical Engineers, pp V005T06A013-V005T06A013. 
33. Töre Yargin G, Crilly N (2015) Information and interaction requirements for software tools supporting analogical design. Artificial Intelligence for Engineering Design, Analysis and Manufacturing 29:203-214.

34. Shneiderman B (2000) Creating Creativity: User Interfaces for Supporting Innovation. ACM Trans Comput-Hum Interact 7:114-138. 